Article

\title{
Genetic Susceptibility to Chronic Liver Disease in Individuals from Pakistan
}

\author{
Asad Mehmood Raja ${ }^{1}$, Ester Ciociola ${ }^{2}$, Imran Nazir Ahmad ${ }^{3}$, Faisal Saud Dar ${ }^{4}$, \\ Syed Muhammad Saqlan Naqvi ${ }^{1}$, Muhammad Moaeen-ud-Din ${ }^{5}$, Ghazala Kaukab Raja ${ }^{1}$, \\ Stefano Romeo ${ }^{2,6,7, *}$ and Rosellina Margherita Mancina ${ }^{2, *}$
}

1 University Institute of Biochemistry and Biotechnology, Pir Mehr Ali Shah Arid Agriculture University Rawalpindi, Rawalpindi 46300, Pakistan; asadscm750@gmail.com (A.M.R.); saqlan@uaar.edu.pk (S.M.S.N.); ghazala@uaar.edu.pk (G.K.R.)

2 Department of Molecular and Clinical Medicine, The Sahlgrenska Academy at the University of Gothenburg, Wallenberg Laboratory, 41345 Gothenburg, Sweden; ester.ciociola@wlab.gu.se

3 Department of Pathology and Laboratory Medicine, Shifa International Hospitals Ltd., Islamabad 44790, Pakistan; imranazir@hotmail.com

4 Liver Transplantation, Hepatobiliary and Pancreatic Services Unit, Shifa International Hospitals Ltd., Islamabad 44790, Pakistan; faisal.saud.dar@gmail.com

5 Department of Animal Breeding and Genetics/National Center for Livestock Breeding, Genetics \& Genomics, Pir Mehr Ali Shah Arid Agriculture University Rawalpindi, Rawalpindi 46300, Pakistan; m.moaeenuddin@uaar.edu.pk

6 Department of Cardiology, Sahlgrenska University Hospital, 41345 Gothenburg, Sweden

7 Clinical Nutrition Unit, Department of Medical and Surgical Sciences, University Magna Graecia, 88100 Catanzaro, Italy

* Correspondence: stefano.romeo@wlab.gu.se (S.R.); rosellina.mancina@wlab.gu.se (R.M.M.); Tel.: +46-(0)313-426-735 (S.R.); +46-(0)31342186 (R.M.M.)

Received: 8 April 2020; Accepted: 15 May 2020; Published: 18 May 2020

\begin{abstract}
Chronic liver disease, with viral or non-viral etiology, is endemic in many countries and is a growing burden in Asia. Among the Asian countries, Pakistan has the highest prevalence of chronic liver disease. Despite this, the genetic susceptibility to chronic liver disease in this country has not been investigated. We performed a comprehensive analysis of the most robustly associated common genetic variants influencing chronic liver disease in a cohort of individuals from Pakistan. A total of 587 subjects with chronic liver disease and 68 healthy control individuals were genotyped for the HSD17B13 rs7261356, MBOAT7 rs641738, GCKR rs1260326, PNPLA3 rs738409, TM6SF2 rs58542926 and $P P P 1 R 3 B$ rs 4841132 variants. The variants distribution between case and control group and their association with chronic liver disease were tested by chi-square and binary logistic analysis, respectively. We report for the first time that $H S D 17 B 13$ variant results in a $50 \%$ reduced risk for chronic liver disease; while MBOAT7; GCKR and PNPLA3 variants increase this risk by more than $35 \%$ in Pakistani individuals. Our genetic analysis extends the protective role of the HSD17B13 variant against chronic liver disease and disease risk conferred by the MBOAT7; GCKR and PNPLA3 variants in the Pakistani population.
\end{abstract}

Keywords: NAFLD; Asia; ADPN; adiponutrin; TMC4; LPIAT1

\section{Introduction}

Chronic liver disease, including viral and non-viral etiology, is endemic in many countries and is a growing burden for society and health-care systems. After the reduction of viral infections in the last 20 years in Western countries, non-viral liver disease is the most common chronic liver disease 
worldwide [1,2]. However, irrespective of the cause, the burden of this disease in many Middle Eastern and Asian countries is continuously rising [3]. Among Asian countries, with 9-10 million people having viral infection [3] and 10-fold more having non-viral liver disease [4], Pakistan represents the country with the highest prevalence of chronic liver disease.

Chronic liver disease has a strong genetic component $[5,6]$. Among all the genetic determinants of chronic liver disease, the Patatin-like phospholipase domain-containing protein 3 (PNPLA3, also known as Adiponutrin [ADPN]) rs738409 (I148M) [7], Membrane Bound O-Acyltransferase Domain Containing 7 (MBOAT7, also known as Lysophosphatidylinositol-acyltransferase-1 [LPIAT1]) rs641738 [8-10], Glucokinase regulator (GCKR) rs1260326 (P446L) [11] and Transmembrane 6 Superfamily Member 2 (TM6SF2) rs58542926 (E167K) [12,13] represent the most robust and widely validated genetic factors increasing the susceptibility to chronic liver disease. Recently, the Hydroxysteroid 17-Beta Dehydrogenase 13 (HSD17B13) rs7261356 [14,15] and the Protein Phosphatase 1 Regulatory Subunit 3B (PPP1R3B) rs4841132 [16,17] have been shown to confer protection against liver disease, at least in at-risk individuals, instead. The proteins encoded by these genes are all involved in the hepatic lipid metabolism. More specifically: PNPLA3 is a lipase localized on the hepatic lipid droplets surface [18] with a triglyceride hydrolase activity (in hepatocytes) $[19,20]$ and a retinyl-palmitate lipase activity (in hepatic stellate cells) [21]; MBOAT7 is a transmembrane acyltransferase protein localized on the endoplasmic reticulum, mitochondria-associated membranes and lipid droplets [8,22], involved in the hepatic phospholipids remodeling [23] and in a non-canonical hepatic triglyceride synthesis pathway fuelled by the phosphatidylinositol turnover [24]; GCKR is involved in the hepatic glucose metabolism [25] and responsible of inverse modulation of fasting plasma glucose and triglyceride levels [26,27]; TM6SF2 is involved in the APOB lipidation and modulates the hepatic lipid droplets secretion of triglycerides through very-low-density lipoproteins (VLDL) [13,28-30]; HSD17B13 is expressed on the hepatic lipid droplet membrane [14], is involved in the hepatic lipogenesis and modulates lipid droplets number and size [31]; PPP1R3B is primarily involved in the hepatic glycogen synthesis and, as results of this, secondarily modulates hepatic triglycerides synthesis through insulin-dependent de novo lipogenesis [16]. The fact that the main genetic determinants of liver disease encode for proteins involved in the hepatic lipid metabolism supports the role of dysregulated lipid metabolism in the pathogenesis of both viral and non-viral liver disease.

Despite the high prevalence of chronic liver disease in Pakistan, the genetic susceptibility to this condition in this country has not been investigated.

In this work, we performed a comprehensive analysis of the most robustly associated common genetic variants influencing chronic liver disease in a cohort of 655 Pakistani individuals comprising 587 individuals with chronic liver disease and 68 healthy controls. We showed for the first time a lower frequency of the minor and protective allele for HSD17B13 variant and a higher frequency of the minor and risk allele for MBOAT7 and GCKR in those with chronic disease. We also confirmed higher frequency of the risk allele for PNPLA3 in individuals with chronic disease as compared to healthy controls.

\section{Results}

A total of 655 Pakistani individuals comprising 587 individuals with chronic liver disease and 68 healthy controls were included in the present study (Table 1). Individuals from the two study groups were all adults with a mean BMI of $26 \mathrm{~kg} / \mathrm{m}^{2}$ and a higher proportion of men. In the case group, the majority of the individuals were affected by viral chronic liver disease ( $89 \%$ viral vs. $11 \%$ with non-viral etiology), 34\% had hepatocellular carcinoma (HCC) and $66 \%$ had cirrhosis. Additionally, compared to the control group, individuals from the case group had a higher proportion of men, higher ALT and AST, and lower total cholesterol, LDL, HDL and triglycerides. 
Table 1. Clinical characteristics of the two study groups.

\begin{tabular}{cccc}
\hline Characteristic & Case & Control & $p$-Value \\
\hline $\mathrm{N}$ & 587 & 68 & \\
Age, Years & $48 \pm 11$ & $46 \pm 12$ & 0.166 \\
Male gender, $\mathrm{n}(\%)$ & $476(81)$ & $42(62)$ & $2.1 \times 10^{-4}$ \\
BMI, Kg/m ${ }^{2}$ & $26 \pm 5$ & $26 \pm 4$ & 0.290 \\
Cholesterol, mg/dL & $88 \pm 40$ & $167 \pm 35$ & $2.3 \times 10^{-45}$ \\
LDL, mg/dL & $51 \pm 32$ & $96 \pm 41$ & $1.9 \times 10^{-23}$ \\
HDL, mg/dL & $19 \pm 12$ & $40 \pm 9$ & $1.2 \times 10^{-44}$ \\
Triglyceride, mg/dL & $69(54-100)$ & $154(120-191)$ & $1.7 \times 10^{-25}$ \\
ALT, IU/L & $66(54-84)$ & $28(22-34)$ & $7.1 \times 10^{-73}$ \\
AST, IU/L & $61(47-78)$ & $29(23-32)$ & $2.7 \times 10^{-64}$ \\
NASH/Viral disease, $\mathrm{n}(\%)$ & $62 / 522(11 / 89)$ & - & - \\
HCC/Cirrhosis, $\mathrm{n}(\%)$ & $197 / 390(34 / 66)$ & - & - \\
\hline
\end{tabular}

For continuous traits, data are shown as mean and standard deviation (normally distributed traits) or as median and quartile range (non-normally distributed traits). Gender is shown as number and proportion. P-values for continuous traits were calculated by linear regression analysis adjusted for age, gender and BMI when appropriate. $p$-value for gender distribution was calculated by Chi-square. After Bonferroni multiple testing correction, only $p<$ $0.005\left(5.0 \times 10^{-3}\right)$ was considered significant.

\subsection{The Frequency of Risk Alleles for Liver Disease Is Higher in Individuals with Chronic Liver Disease}

To assess the genetic susceptibility to chronic liver disease in the Pakistani population, we compared the distribution of the minor allele frequencies of the variants between the case and control group. For these analyses, we included in the control group additional data on frequency distribution from 96 additional Pakistani individuals (Punjabi in Lahore) from 1000 Genomes Project (Ensembl release 99-January 2020).

The frequency of the minor and protective allele for the HSD17B13 variant was lower in individuals from the case group as compared to the control group (MAF $=0.12$ vs. 0.21 , respectively, $p$-value $=1.7 \times 10^{-5}$, Figure $1 \mathrm{a}$ ), suggesting a protective role of this allele against chronic liver disease. Additionally, the frequency of the minor and risk allele for MBOAT7, GCKR, and PNPLA3 was higher compared to the control group ( $p$-value $=0.017,0.036$ and 0.003 for the three variants, respectively), suggesting a chronic liver disease risk susceptibility conferred by these variants. We found no difference in the minor allele frequencies between individuals from the case and control group for TM6SF2 nor for $P P P 1 R 3 B$ variant. Results were similar when including only the 68 healthy control individuals recruited for the present study (data not shown).

\subsection{The HSD17B13 Minor Allele Reduces the Risk for Chronic Liver Disease}

To assess the risk for liver disease conferred by each variant, we performed univariate binary logistic regression analyses. We found that the HSD17B13 variant was associated with an approximately $50 \%$ reduced risk for chronic liver disease (OR 0.49, CI 0.35-0.69, $p$-value $=2.6 \times 10^{-5}$ ), MBOAT7 and GCKR variants were associated with an approximately $35 \%$ increased risk for chronic liver disease $(\mathrm{OR} 1.35, \mathrm{CI}: 1.06-1.73, p$-value $=0.017$, and OR 1.36, CI: 1.02-1.81, $p$-value $=0.036$ respectively $)$, and PNPLA3 variant was associated with more than $50 \%$ increased risk for chronic liver disease (OR 1.54, CI: 1.162.04, $p$-value $=0.003$ ) (Figure $1 b)$. 

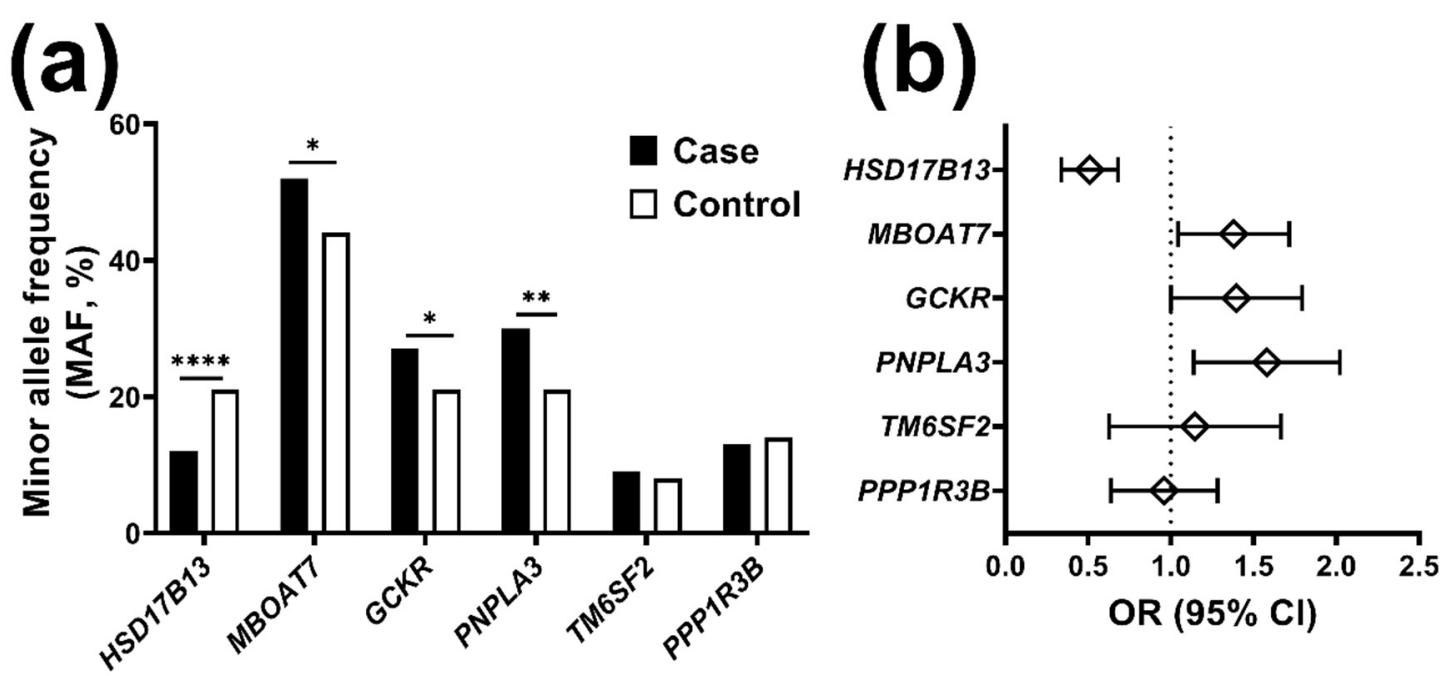

Figure 1. Minor allele frequency of main genetic determinants of liver disease and the corresponding risk for chronic liver disease in Pakistani individuals. (a) Minor allele frequency of main genetic determinants of liver disease stratified by case and control group. Data are shown as percentage. P-values calculated by chi-square. (b) The risk for chronic liver disease conferred by the minor allele of the main genetic determinants of chronic liver disease expressed as Odds ratio (OR) and its 95\% confidence interval (CI). The risk was estimated by binary logistic regression under an additive genetic model with the exception of TM6SF2 where a dominant genetic model has been assumed, considering the relative lower MAF. Case group: $n=587$ individuals with chronic liver disease $(n=522$ viral and 62 non-viral). Control group: $n=164$ individuals without liver disease $(n=68$ recruited in the present study plus 96 Punjabi individuals reported on 1000 Genomes Project ((Ensembl release 99-January 2020)). Abbreviations: HSD17B13, Hydroxysteroid 17-Beta Dehydrogenase 13; MBOAT7, Membrane Bound O-Acyltransferase Domain Containing 7; PNPLA3, Patatin-like phospholipase domain-containing protein 3; CGKR, Glucokinase regulator; TM6SF2, Transmembrane 6 Superfamily Member 2; PPP1R3B, Protein Phosphatase 1 Regulatory Subunit 3B. ${ }^{*} p<0.05{ }^{* *} p<0.005 ;{ }^{* * *} p<0.0001$; $* * * * 0<0.00005$.

\section{Discussion}

In the present study, we examined six common genetic variants robustly associated with chronic liver disease in individuals from Pakistan. We compared the distribution of the minor allele frequency of these variants between 587 individuals with and 164 individuals without chronic liver disease $n=68$ recruited in the present study plus 96 Punjabi individuals reported on 1000 Genomes Project (Ensembl release 99-January 2020)). As expected, and consistently with the presence of chronic liver disease, individuals from the case group had higher ALT and AST compared to individuals from the control group. Interestingly, individuals from the case group had lower total cholesterol, LDL, HDL and triglycerides compared to those from the control group. Our finding is in line with previously reported data showing that individuals with HCV or HBV-related cirrhosis have lower lipid profile (including total, LDL, and HDL cholesterol, and triglyceride) compared to healthy control individuals $[32,33]$ and that serum lipid levels diminish linearly with the progression of liver damage [34].

We showed for the first time that HSD17B13 variant is protective while MBOAT7 and GCKR confer increased risk of chronic liver disease in Pakistani individuals.

Of note, for HSD17B13 sequence variant conferred approximately $50 \%$ reduced risk for chronic liver disease in this cohort. HSD17B13 rs7261356 is a splice loss-of-function variant resulting in the synthesis of a truncated protein with reduced expression levels [14]. It has been previously shown that this variant reduced the risk for liver disease in different ethnicities and regardless the etiology of liver disease. Indeed, the protective effect of the HSD17B13 variant against non-alcoholic liver disease has already been shown in individuals of European [14], African [35] and Hispanics/Latinos descent [35,36]. 
The association between HSD17B13 variant and reduced risk for advanced liver disease has also been shown in viral [37], alcoholic [38], portal hypertension [39], and in Wilson's disease [40]. Despite the number of studies on HSD17B13 and liver disease in American and European countries, to our knowledge there are no data available so far in Asian countries.

The present study is the first extending the association between HSD17B13 and protection against chronic liver disease to an Asian population, namely Pakistani. Our data are consistent with those reported for other ethnicities and, together with them, underline the potential of HSD17B13 as a therapeutic target [41] to treat liver disease irrespective of ethnicity, and its role in the genetic susceptibility to chronic liver disease.

With the present study, we also show for the first time that the minor and risk allele for the $M B O A T 7$ rs641738 and for GCKR rs1260326 variants are enriched in Pakistani individuals with chronic liver disease and each of them induces a $35 \%$ increased risk for chronic liver disease. The MBOAT7 variant, originally reported as intergenic variant between $M B O A T 7$ and Transmembrane Channel Like 4 (TMC4), is located in the $3^{\prime} \mathrm{UTR}$ of the MBOAT7 gene and results in its decreased expression level, which consequently induces liver disease by altering phosphatidylinositol remodeling [8] and by triggering a novel non-canonical hepatic triglyceride synthesis pathway fuelled by phospholipid turnover [24]. Our findings are in line with results previously reported in other ethnicities describing the association between the $M B O A T 7$ variant and chronic liver disease and suggest that the rs641738 is the causal genetic variant influencing expression level of MBOAT7 and increasing the risk to liver disease $[8,9]$.

The GCKR rs1260326 is a missense variant encoding for a proline $(\mathrm{P})$ to leucine $(\mathrm{L})$ at position 446 of the protein (P446L). The minor allele (L) for this variant has been previously associated with higher prevalence of liver disease and lower prevalence of type-2 diabetes or lower levels of glycaemic traits [11]. Our findings confirm the role of the GCKR variant in the genetic susceptibility to liver disease. However, glycaemic traits were not available for our study groups.

The PNPLA3 rs738409 is a missense variant encoding for an isoleucine to methionine substitution at position 148 of the protein (I148M). It increases the susceptibility to liver disease by affecting both triglyceride [18,42], and retinol remodeling in the liver [21,43], and increasing the production of profibrotic proteins from hepatic stellate cells $[44,45]$. Very recently, it has been highlighted that inhibition of the mutant Pnpla3 may be used as a therapeutic target to treat fatty liver disease $[46,47]$. This variant represents the first and the most widely validated genetic determinant of liver disease [7]. Its role in liver disease onset and progression has been already demonstrated in different ethnicities, including some from Asia [48-53]. We found that the frequency of PNPLA3 minor allele was higher in individuals with chronic liver disease than in healthy controls and that each minor allele was associated with more than $50 \%$ increased risk for chronic liver disease. Our findings are in line with previously reported data from both European and Asian populations and, for the first time, extend the association between PNPLA3 variant and chronic liver disease in a Pakistani population.

We additionally tested the effect of TM6SF2 rs58542926 and PPP1R3B rs4841132 variant on the genetic susceptibility to chronic liver disease in the Pakistani population. The TM6SF2 rs58542926 encodes for a glutamic acid to lysine amino acidic substitution at position 167 of the protein (E167K). This variant increases the risk for chronic liver disease by affecting the secretion of APO-B-containing lipoproteins $[12,13]$. On the other hands, the PPP1R3B rs4841132 is located 175 kilobase $(\mathrm{kb})$ upstream of the $P P P 1 R 3 B$ coding region and is associated with reduced susceptibility to chronic liver disease in at risk individuals $[6,16,17]$.

In our study, we did not detect any significant difference in the distribution of these two variants between individuals from the case and the control group although the trend was in the expected direction. Indeed, we found that the MAF for the TM6SF2 variant was slightly higher while the MAF for the $P P P 1 R 3 B$ variant was slightly lower in the case group compared to healthy individuals. This result is probably due to a lack of statistical power.

The tested variants are widely recognized as the main genetic determinants of liver disease. Of note, all the tested genes encode for proteins involved in the hepatic lipid metabolism. This supports 
the role of dysregulated lipid metabolism in the pathogenesis of both non-viral and viral liver disease. Of note, in HCV-related liver disease, there is a growing body of evidence linking the HCV life cycle and hepatocytes' lipid metabolism [54]. More specifically, it has been shown that the HCV core accumulates around the hepatocytes' lipid droplets (storage of triglycerides) [55] and inhibits the secretion of VLDL [56], the APOB-containing triglycerides-rich lipoproteins. In the lipid droplets, HCV virus particles are packed with APOB and then secreted as a lipo-viral particle (LVP) in the blood circulation. Then, these particles may enter again into hepatocytes through the LDL-receptor [57], the surface receptor that is responsible for the hepatic APOB-mediated LDL-cholesterol uptake. All this together suggests that APOB is deeply involved in the HCV life cycle [58]. Many studies investigated the genetic association between $A P O B$ and $\mathrm{HCV}$-related viral disease showing that variants in $A P O B$ increase the susceptibility to $\mathrm{HCV}$ infection $[59,60]$. So far, variants on $A P O B$ were mainly investigated for associations with cardiovascular disease showing a different effect based on population ethnicity [61]. It would be important to investigate if this could be the case for the susceptibility to HCV as well. Additionally, it would be important to test whether APOB polymorphisms may modulate the risk or the protection of chronic liver disease conferred by variants on HSD17B13, MBOAT7, PNPLA3, or CGKR.

The relatively low sample size together with the absence of glycemic traits and the use of a combined cohort with different etiologies (viral and non-viral), represent the main limitation of this study. Additionally, the lack of clinical and anthropometric data for individuals from the 1000 Genome project, does not allow to perform multivariate analysis to evaluate the contribution of each tested minor allele on the risk for liver disease independently from confounders. The major strength of this study, on the other hand, is represented by the number of common variants tested, which provide comprehensive analyses of the genetic susceptibility to chronic liver disease in the Pakistani population.

In conclusion, our genetic analysis of common variants related to chronic liver disease extends the protective role of the $H S D 17 B 13$ variant against chronic liver disease and the increased susceptibility risk to this disease conferred by the presence of the MBOAT7 rs641738, GCKR rs1260326 or PNPLA3 rs738409 variant in a Pakistani population. Considering the potential lack of power of our study to detect differences in the TM6SF2 rs58542926 and PPP1R3B rs4841132 frequency between the two study groups, larger studies are recommended to test the contribution of these variants on chronic liver disease in Pakistani population.

\section{Materials and Methods}

\subsection{Study Cohort}

For the case group: a total of 587 consecutive Pakistani individuals with chronic liver disease $(n=$ 522 viral and 62 non-viral), who underwent living donor liver transplantation (LDLT) for end stage liver disease, were recruited from April 2012 to July 2018 at the Liver Transplantation, Hepatobiliary and Pancreatic Services unit, Shifa International Hospitals Ltd. (Islamabad, Pakistan). All causes of cirrhosis or hepatocellular carcinoma with the exception for fulminant hepatic failure were considered eligible for the present study. Diagnosis of liver disease was performed based on clinical history, biochemical parameters and histopathology reports.

For the control group: a total of 68 healthy individuals without liver disease of any etiology and without metabolic syndrome, defined as a combination of complex risk factors including central obesity $\left(\mathrm{BMI}>29.9 \mathrm{~kg} / \mathrm{m}^{2}\right)$, hypertension ( $\mathrm{SBP} \geq 130 \mathrm{mmHg} / \mathrm{DBP} \geq 85 \mathrm{mmHg}$ ), dysglycemia (fasting blood glucose $>100 \mathrm{mg} / \mathrm{dL}$ ), and dyslipidemia (triglycerides $>200 \mathrm{mg} / \mathrm{dL}$ and HDL $<40 \mathrm{mg} / \mathrm{dL}$ ) [62], were randomly recruited from general Pakistani population. To this group, for the minor allele frequency comparisons between case and control group, genotypes information from 96 Punjabi individuals reported on 1000 Genomes Project (Ensembl release 99-January 2020)) were included. The 1000 Genome project is a selection-bias-free population-based collection of reference genomic sequences aiming to provide a comprehensive description of common human genetic variations of individuals 
from multiple populations [63]. Thus, individuals from the 1000 Genome project represents a correct setting to evaluate if there is an enrichment of a target risk variant in a selected study group compared to the general population. However, information on phenotype or medical conditions of the study participants are held in confidence by the local investigators and not publicly available.

Information about age, gender and BMI were registered at the time of enrollment for all the recruited study participants. Measurement of clinical parameters including lipid profile (total Cholesterol, LDL, HDL and Triglyceride), transaminases (ALT and AST), and viral serology (Hepatitis B surface antigen, Hepatitis B core antibody, Hepatitis C virus antibody and Hepatitis Delta virus antibody) were performed on freshly isolated blood samples and under starvation conditions at the time of transplantation (case group) or at the time of enrollment (control group).

Formalin Fixed Paraffin Embedded (FFPE) blocks of explant liver for DNA extraction were collected from the pathology laboratory at the time of transplantation for individuals from the case group.

Extra EDTA-containing blood tubes for DNA extraction were collected at the time of the enrollment for the individuals from the control group.

Informed written consent was obtained from each subject, and the study protocol was approved by the PMAS Arid Agriculture University Rawalpindi's (PMAS AAUR) Ethics Committee for use of Human Subjects and Institutional Review Board and Ethics Committee (IRB \& EC) of Shifa International Hospitals Ltd. (Islamabad) IRB\# 834-109-2017.

\subsection{DNA Extraction and Genotyping}

DNA was extracted from Formalin-Fixed Paraffin-Embedded (FFPE) liver specimens using RecoverAll ${ }^{\mathrm{TM}}$ total nucleic acid isolation kit for FFPE (Invitrogen ${ }^{\mathrm{TM}}$, ThermoFisher Scientific, USA) according to manufactures' instructions (case group), or from EDTA-containing blood by the salting-out method [64] (control group).

HSD17B13 rs7261356, MBOAT7 rs641738, GCKR rs1260326, PNPLA3 rs738409, TM6SF2 rs58542926, and the PPP1R3B rs 4841132 variants were genotyped in duplicate (with a $100 \%$ concordance between duplicate) by TaqMan 5'-nuclease assays (Thermo Fisher Scientific, Waltham, MA, USA). Assays were already available and directly provided by Thermo Fisher Scientific (TaqMan) for all of the target genetic variants except for HSD17B13 rs7261356 for which a custom assay was designed as follows: Context sequence: TATTTGGGTGTTCTGTGCTGTACTT[*/A]ACTTCTGTAGTCTCAGAAAGATATT; forward primer: GCTCTATTGGTGTTTTAGTATTTGGGTGTT; reverse primer: GAAGTCTGATAGA TGGAATACTTACCAATAAGA. Post-PCR allelic discrimination was performed by measuring allele-specific fluorescence using a CFX384 Real-Time System (Bio-Rad Laboratories Inc, Hercules, CA, USA). In the subset of healthy control individuals, Hardy Weinberg equilibrium was preserved for all the variants. In the subset of the individuals with chronic liver disease, Hardy Weinberg equilibrium was deviated for PNPLA3 rs738409, GCKR rs1260326, and PPP1R3B rs4841132 probably due to the bias of selection.

\subsection{Statistical Analysis}

For descriptive statistics, continuous traits are shown as mean and standard deviation (normally distributed traits) or as median and quartile range (non-normally distributed traits), gender is shown as number and proportion. P-values for comparison of continuous traits between case and control group were calculated by linear regression analysis adjusted for age, gender and BMI when appropriate. Non-normally distributed traits have been log-transformed before entering the model. P-value for gender distribution was calculated by Chi-square. After Bonferroni multiple testing correction, only $p<0.005\left(5.0 \times 10^{-3}\right)$ was considered significant.

Data for minor allele frequency (MAF) are shown as percentage. Data for the risk for liver disease conferred by the minor allele of the main genetic determinants of chronic liver disease are expressed as Odds ratio (OR) and its $95 \%$ confidence interval (CI). P-values for comparison of MAF between 
case and control group have been calculated by Chi-square. The risk for chronic liver disease has been evaluated by binary logistic analysis under an additive genetic model (except for TM6SF2 variant where a dominant genetic model has been assumed considering the relatively low MAF).

Statistical analyses were carried out using the IBM Statistical Package for Social Sciences (IBM SPSS, version 26, Inc. Chicago, IL, USA). $p$-values $<0.05$ were considered statistically significant.

Author Contributions: Conceptualization, S.R. and R.M.M.; data curation, I.N.A., F.S.D., S.M.S.N., M.M.-u.-D. and G.K.R.; formal analysis, A.M.R., E.C. and R.M.M.; funding acquisition, S.R.; investigation, S.R.; supervision, S.R. and R.M.M.; writing-original draft, R.M.M.; writing-review and editing, A.M.R., E.C., I.N.A., F.S.D., S.M.S.N, M.M.D., G.K. and S.R. All authors have read and agreed to the published version of the manuscript.

Funding: This research was funded by project grants from the Swedish Research Council (Vetenskapsradet (VR), 2016-01527), the Swedish state under the Agreement between the Swedish government and the county councils (the ALF agreement, SU 2018-04276), the Novonordisk Foundation Grant for Excellence in Endocrinology (Excellence Project, 9321-430), the Swedish Diabetes Foundation (DIA 2017-205), the Swedish Heart Lung Foundation (20120533), the Wallenberg Academy Fellows from the Knut and Alice Wallenberg Foundation (KAW 2017.0203), the Novonordisk Project grants in Endocrinology and Metabolism, Astra Zeneca Agreement for Research, and the Swedish Foundation for Strategic Research (SSF ITM17-0384) (S.R.); and the International Research Support Initiative Program (1-8/HEC/HRD/2018/8121) awarded by the Higher Education Commission of Pakistan (PIN: IRSIP 42 BMS 25) (A.M.R.).

Conflicts of Interest: The authors declare no conflict of interest.

\section{Abbreviations}

$\begin{array}{ll}\text { ALT } & \text { Alanine transaminase } \\ \text { AST } & \text { Aspartate transaminase } \\ \text { BMI } & \text { Body mass index } \\ \text { CGKR } & \text { Glucokinase regulator } \\ \text { CI } & \text { Confidence interval } \\ \text { FFPE } & \text { Formalin-Fixed Paraffin-Embedded } \\ \text { HCC } & \text { Hepatocellular carcinoma } \\ \text { HDL } & \text { High-density lipoproteins } \\ \text { HSD17B13 } & \text { Hydroxysteroid 17-Beta Dehydrogenase 13 } \\ \text { LDL } & \text { Low-density lipoproteins } \\ \text { MBOAT7 } & \text { Membrane Bound O-Acyltransferase Domain Containing 7 } \\ \text { OR } & \text { Odds ratio. } \\ \text { PNPLA3 } & \text { Patatin-like phospholipase domain-containing protein 3 } \\ \text { PPP1R3B } & \text { Protein Phosphatase 1 Regulatory Subunit 3B } \\ \text { TM6SF2 } & \text { Transmembrane 6 Superfamily Member 2 }\end{array}$

\section{References}

1. Rinella, M.E. Nonalcoholic fatty liver disease: A systematic review. JAMA 2015, 313, 2263-2273. [CrossRef] [PubMed]

2. Lavanchy, D. Evolving epidemiology of hepatitis C virus. Clin. Microbiol. Infect. 2011, 17, 107-115. [CrossRef] [PubMed]

3. Hajarizadeh, B.; Grebely, J.; Dore, G.J. Epidemiology and natural history of HCV infection. Nat. Rev. Gastroenterol. Hepatol. 2013, 10, 553-562. [CrossRef] [PubMed]

4. Shah, A.S.; Khan, S.; Rahim, H.; Chishti, K.A.; Khan, A.G. Prevalence of non alcoholic fatty liver and non alcoholic Steatohepatitis in Peshawar Cantonment, Khyber Pakhtunkhwa, Pakistan. Pak. J. Pharm. Sci. 2018, 31, 193-198.

5. Valenti, L.V.C.; Baselli, G.A. Genetics of Nonalcoholic Fatty Liver Disease: A 2018 Update. Curr. Pharm. Des. 2018, 24, 4566-4573. [CrossRef] [PubMed]

6. Romeo, S.; Sanyal, A.; Valenti, L. Leveraging Human Genetics to Identify Potential New Treatments for Fatty Liver Disease. Cell Metab. 2020, 31, 35-45. [CrossRef] 
7. Romeo, S.; Kozlitina, J.; Xing, C.; Pertsemlidis, A.; Cox, D.; Pennacchio, L.A.; Boerwinkle, E.; Cohen, J.C.; Hobbs, H.H. Genetic variation in PNPLA3 confers susceptibility to nonalcoholic fatty liver disease. Nat. Genet. 2008, 40, 1461-1465. [CrossRef]

8. Mancina, R.M.; Dongiovanni, P.; Petta, S.; Pingitore, P.; Meroni, M.; Rametta, R.; Borén, J.; Montalcini, T.; Pujia, A.; Wiklund, O.; et al. The MBOAT7-TMC4 Variant rs641738 Increases Risk of Nonalcoholic Fatty Liver Disease in Individuals of European Descent. Gastroenterology 2016. [CrossRef]

9. Buch, S.; Stickel, F.; Trépo, E.; Way, M.; Herrmann, A.; Nischalke, H.D.; Brosch, M.; Rosendahl, J.; Berg, T.; Ridinger, M.; et al. A genome-wide association study confirms PNPLA3 and identifies TM6SF2 and MBOAT7 as risk loci for alcohol-related cirrhosis. Nat. Genet. 2015. [CrossRef]

10. Viitasalo, A.; Eloranta, A.M.; Atalay, M.; Romeo, S.; Pihlajamäki, J.; Lakka, T.A. Association of MBOAT7 gene variant with plasma ALT levels in children: The PANIC study. Pediatr. Res. 2016, 80, 651-655. [CrossRef]

11. Speliotes, E.K.; Yerges-Armstrong, L.M.; Wu, J.; Hernaez, R.; Kim, L.J.; Palmer, C.D.; Gudnason, V.; Eiriksdottir, G.; Garcia, M.E.; Launer, L.J.; et al. Genome-wide association analysis identifies variants associated with nonalcoholic fatty liver disease that have distinct effects on metabolic traits. PLoS Genet. 2011, 7, e1001324. [CrossRef]

12. Dongiovanni, P.; Petta, S.; Maglio, C.; Fracanzani, A.L.; Pipitone, R.; Mozzi, E.; Motta, B.M.; Kaminska, D.; Rametta, R.; Grimaudo, S.; et al. Transmembrane 6 superfamily member 2 gene variant disentangles nonalcoholic steatohepatitis from cardiovascular disease. Hepatology 2015, 61, 506-514. [CrossRef] [PubMed]

13. Kozlitina, J.; Smagris, E.; Stender, S.; Nordestgaard, B.G.; Zhou, H.H.; Tybjaerg-Hansen, A.; Vogt, T.F.; Hobbs, H.H.; Cohen, J.C. Exome-wide association study identifies a TM6SF2 variant that confers susceptibility to nonalcoholic fatty liver disease. Nat. Genet. 2014, 46, 352-356. [CrossRef] [PubMed]

14. Abul-Husn, N.S.; Cheng, X.; Li, A.H.; Xin, Y.; Schurmann, C.; Stevis, P.; Liu, Y.; Kozlitina, J.; Stender, S.; Wood, G.C.; et al. A Protein-Truncating HSD17B13 Variant and Protection from Chronic Liver Disease. N. Engl. J. Med. 2018, 378, 1096-1106. [CrossRef]

15. Ma, Y.; Belyaeva, O.V.; Brown, P.M.; Fujita, K.; Valles, K.; Karki, S.; de Boer, Y.S.; Koh, C.; Chen, Y.; Du, X.; et al. 17-Beta Hydroxysteroid Dehydrogenase 13 Is a Hepatic Retinol Dehydrogenase Associated With Histological Features of Nonalcoholic Fatty Liver Disease. Hepatology 2019, 69, 1504-1519. [CrossRef]

16. Stender, S.; Smagris, E.; Lauridsen, B.K.; Kofoed, K.F.; Nordestgaard, B.G.; Tybjaerg-Hansen, A.; Pennacchio, L.A.; Dickel, D.E.; Cohen, J.C.; Hobbs, H.H. Relationship between Genetic Variation at PPP1R3B and Liver Glycogen and Triglyceride Levels. Hepatology 2017. [CrossRef] [PubMed]

17. Dongiovanni, P.; Meroni, M.; Mancina, R.M.; Baselli, G.; Rametta, R.; Pelusi, S.; Männistö, V.; Fracanzani, A.L.; Badiali, S.; Miele, L.; et al. Protein phosphatase 1 regulatory subunit 3B gene variation protects against hepatic fat accumulation and fibrosis in individuals at high risk of nonalcoholic fatty liver disease. Hepatol. Commun. 2018, 2, 666-675. [CrossRef]

18. Pirazzi, C.; Adiels, M.; Burza, M.A.; Mancina, R.M.; Levin, M.; Stahlman, M.; Taskinen, M.-R.; Orho-Melander, M.; Perman, J.; Pujia, A.; et al. Patatin-like phospholipase domain-containing 3 (PNPLA3) I148M (rs738409) affects hepatic VLDL secretion in humans and in vitro. J. Hepatol. 2012, 57, 1276-1282. [CrossRef]

19. Pingitore, P.; Pirazzi, C.; Mancina, R.M.; Motta, B.M.; Indiveri, C.; Pujia, A.; Montalcini, T.; Hedfalk, K.; Romeo, S. Recombinant PNPLA3 protein shows triglyceride hydrolase activity and its I148M mutation results in loss of function. Biochim. Biophys. Acta Mol. Cell Biol. Lipids 2014, 1841, 574-580. [CrossRef]

20. He, S.; McPhaul, C.; Li, J.Z.; Garuti, R.; Kinch, L.; Grishin, N.V.; Cohen, J.C.; Hobbs, H.H. A sequence variation (I148M) in PNPLA3 associated with nonalcoholic fatty liver disease disrupts triglyceride hydrolysis. J. Biol. Chem. 2010, 285, 6706-6715. [CrossRef]

21. Pirazzi, C.; Valenti, L.; Motta, B.M.; Pingitore, P.; Hedfalk, K.; Mancina, R.M.; Burza, M.A.; Indiveri, C.; Ferro, Y.; Montalcini, T.; et al. PNPLA3 has retinyl-palmitate lipase activity in human hepatic stellate cells. Hum. Mol. Genet. 2014, 23, 4077-4085. [CrossRef] [PubMed]

22. Caddeo, A.; Jamialahmadi, O.; Solinas, G.; Pujia, A.; Mancina, R.M.; Pingitore, P.; Romeo, S. MBOAT7 is anchored to endomembranes by six transmembrane domains. J. Struct. Biol. 2019. [CrossRef] [PubMed]

23. D'Souza, K.; Epand, R.M. Enrichment of phosphatidylinositols with specific acyl chains. Biochim. Biophys. Acta 2014, 1838, 1501-1508. [CrossRef] [PubMed] 
24. Tanaka, Y.; Shimanaka, Y.; Caddeo, A.; Kubo, T.; Mao, Y.; Kubota, T.; Kubota, N.; Yamauchi, T.; Mancina, R.M.; Baselli, G.; et al. LPIAT1/MBOAT7 depletion increases triglyceride synthesis fueled by high phosphatidylinositol turnover. Gut 2020. [CrossRef]

25. Veiga-da-Cunha, M.; Van Schaftingen, E. Identification of fructose 6-phosphate- and fructose 1-phosphate-binding residues in the regulatory protein of glucokinase. J. Biol. Chem. 2002, 277, 8466-8473. [CrossRef]

26. Orho-Melander, M.; Melander, O.; Guiducci, C.; Perez-Martinez, P.; Corella, D.; Roos, C.; Tewhey, R.; Rieder, M.J.; Hall, J.; Abecasis, G.; et al. Common missense variant in the glucokinase regulatory protein gene is associated with increased plasma triglyceride and C-reactive protein but lower fasting glucose concentrations. Diabetes 2008, 57, 3112-3121. [CrossRef]

27. Saxena, R.; Voight, B.F.; Lyssenko, V.; Burtt, N.P.; de Bakker, P.I.; Chen, H.; Roix, J.J.; Kathiresan, S.; Hirschhorn, J.N.; Daly, M.J.; et al. Genome-wide association analysis identifies loci for type 2 diabetes and triglyceride levels. Science 2007, 316, 1331-1336. [CrossRef]

28. Holmen, O.L.; Zhang, H.; Fan, Y.; Hovelson, D.H.; Schmidt, E.M.; Zhou, W.; Guo, Y.; Zhang, J.; Langhammer, A.; Lochen, M.L.; et al. Systematic evaluation of coding variation identifies a candidate causal variant in TM6SF2 influencing total cholesterol and myocardial infarction risk. Nat. Genet. 2014, 46, 345-351. [CrossRef]

29. Mahdessian, H.; Taxiarchis, A.; Popov, S.; Silveira, A.; Franco-Cereceda, A.; Hamsten, A.; Eriksson, P.; van't Hooft, F. TM6SF2 is a regulator of liver fat metabolism influencing triglyceride secretion and hepatic lipid droplet content. Proc. Natl. Acad. Sci. USA 2014, 111, 8913-8918. [CrossRef]

30. Prill, S.; Caddeo, A.; Baselli, G.; Jamialahmadi, O.; Dongiovanni, P.; Rametta, R.; Kanebratt, K.P.; Pujia, A.; Pingitore, P.; Mancina, R.M.; et al. The TM6SF2 E167K genetic variant induces lipid biosynthesis and reduces apolipoprotein B secretion in human hepatic 3D spheroids. Sci. Rep. 2019, 9, 11585. [CrossRef]

31. Su, W.; Wang, Y.; Jia, X.; Wu, W.; Li, L.; Tian, X.; Li, S.; Wang, C.; Xu, H.; Cao, J.; et al. Comparative proteomic study reveals $17 \beta-H S D 13$ as a pathogenic protein in nonalcoholic fatty liver disease. Proc. Natl. Acad. Sci. USA 2014, 111, 11437-11442. [CrossRef] [PubMed]

32. Pothineni, N.V.; Delongchamp, R.; Vallurupalli, S.; Ding, Z.; Dai, Y.; Hagedorn, C.H.; Mehta, J.L. Impact of hepatitis $C$ seropositivity on the risk of coronary heart disease events. Am. J. Cardiol. 2014, 114, 1841-1845. [CrossRef]

33. Arain, S.Q.; Talpur, F.N.; Channa, N.A.; Ali, M.S.; Afridi, H.I. Serum lipid profile as a marker of liver impairment in hepatitis B Cirrhosis patients. Lipids Health Dis. 2017, 16, 51. [CrossRef] [PubMed]

34. Ghadir, M.R.; Riahin, A.A.; Havaspour, A.; Nooranipour, M.; Habibinejad, A.A. The relationship between lipid profile and severity of liver damage in cirrhotic patients. Hepat. Mon. 2010, 10, 285-288. [PubMed]

35. Kozlitina, J.; Stender, S.; Hobbs, H.H.; Cohen, J.C. HSD17B13 and Chronic Liver Disease in Blacks and Hispanics. N. Engl. J. Med. 2018, 379, 1876-1877. [CrossRef] [PubMed]

36. Kallwitz, E.; Tayo, B.O.; Kuniholm, M.H.; Daviglus, M.; Zeng, D.; Isasi, C.R.; Cotler, S.J. Association of HSD17B13 rs72613567:TA with non-alcoholic fatty liver disease in Hispanics/Latinos. Liver Int. 2020. [CrossRef]

37. Yang, J.; Trépo, E.; Nahon, P.; Cao, Q.; Moreno, C.; Letouzé, E.; Imbeaud, S.; Bayard, Q.; Gustot, T.; Deviere, J.; et al. A 17-Beta-Hydroxysteroid Dehydrogenase 13 Variant Protects From Hepatocellular Carcinoma Development in Alcoholic Liver Disease. Hepatology 2019, 70, 231-240. [CrossRef]

38. Stickel, F.; Lutz, P.; Buch, S.; Nischalke, H.D.; Silva, I.; Rausch, V.; Fischer, J.; Weiss, K.H.; Gotthardt, D.; Rosendahl, J.; et al. Genetic variation in HSD17B13 reduces the risk of developing cirrhosis and hepatocellular carcinoma in alcohol misusers. Hepatology 2019. [CrossRef]

39. Scheiner, B.; Stättermayer, A.F.; Schwabl, P.; Bucsics, T.; Paternostro, R.; Bauer, D.; Simbrunner, B.; Schmidt, R.; Marculescu, R.; Ferlitsch, A.; et al. Impact of HSD17B13 rs72613567 genotype on hepatic decompensation and mortality in patients with portal hypertension. Liver Int. 2020, 40, 393-404. [CrossRef]

40. Ferenci, P.; Pfeiffenberger, J.; Stättermayer, A.F.; Stauber, R.E.; Willheim, C.; Weiss, K.H.; Munda-Steindl, P.; Trauner, M.; Schilsky, M.; Zoller, H. HSD17B13 truncated variant is associated with a mild hepatic phenotype in Wilson's Disease. JHEP Rep. 2019, 1, 2-8. [CrossRef]

41. Stender, S.; Romeo, S. HSD17B13 as a promising therapeutic target against chronic liver disease. Liver Int. 2020. [CrossRef] [PubMed] 
42. Mancina, R.M.; Matikainen, N.; Maglio, C.; Söderlund, S.; Lundbom, N.; Hakkarainen, A.; Rametta, R.; Mozzi, E.; Fargion, S.; Valenti, L.; et al. Paradoxical Dissociation between Hepatic Fat Content and De Novo Lipogenesis Due to PNPLA3 Sequence Variant. J. Clin. Endocrinol. Metab. 2015, 100, E821-E825. [CrossRef] [PubMed]

43. Mondul, A.; Mancina, R.M.; Merlo, A.; Dongiovanni, P.; Rametta, R.; Montalcini, T.; Valenti, L.; Albanes, D.; Romeo, S. PNPLA3 1148M Variant Influences Circulating Retinol in Adults with Nonalcoholic Fatty Liver Disease or Obesity. J. Nutr. 2015, 145, 1687-1691. [CrossRef] [PubMed]

44. Pingitore, P.; Dongiovanni, P.; Motta, B.M.; Meroni, M.; Lepore, S.M.; Mancina, R.M.; Pelusi, S.; Russo, C.; Caddeo, A.; Rossi, G.; et al. PNPLA3 overexpression results in reduction of proteins predisposing to fibrosis. Hum. Mol. Genet. 2016. [CrossRef] [PubMed]

45. Bruschi, F.V.; Claudel, T.; Tardelli, M.; Caligiuri, A.; Stulnig, T.M.; Marra, F.; Trauner, M. The PNPLA3 I148M variant modulates the fibrogenic phenotype of human hepatic stellate cells. Hepatology 2017, 65, 1875-1890. [CrossRef] [PubMed]

46. Lindén, D.; Ahnmark, A.; Pingitore, P.; Ciociola, E.; Ahlstedt, I.; Andréasson, A.C.; Sasidharan, K.; Madeyski-Bengtson, K.; Zurek, M.; Mancina, R.M.; et al. Pnpla3 silencing with antisense oligonucleotides ameliorates nonalcoholic steatohepatitis and fibrosis in Pnpla3 I148M knock-in mice. Mol. Metab. 2019, 22, 49-61. [CrossRef]

47. Colombo, M.; Pelusi, S. Towards Precision Medicine in Nonalcoholic Fatty Liver Disease with PNPLA3 as a Therapeutic Target. Gastroenterology 2019, 157, 1156-1157. [CrossRef]

48. Sookoian, S.; Pirola, C.J. Meta-analysis of the influence of I148M variant of patatin-like phospholipase domain containing 3 gene (PNPLA3) on the susceptibility and histological severity of nonalcoholic fatty liver disease. Hepatology 2011, 53, 1883-1894. [CrossRef]

49. Kitamoto, T.; Kitamoto, A.; Yoneda, M.; Hyogo, H.; Ochi, H.; Nakamura, T.; Teranishi, H.; Mizusawa, S.; Ueno, T.; Chayama, K.; et al. Genome-wide scan revealed that polymorphisms in the PNPLA3, SAMM50, and PARVB genes are associated with development and progression of nonalcoholic fatty liver disease in Japan. Hum. Genet. 2013. [CrossRef]

50. Li, Y.; Xing, C.; Tian, Z.; Ku, H.C. Genetic variant I148M in PNPLA3 is associated with the ultrasonography-determined steatosis degree in a Chinese population. BMC Med. Genet. 2012, 13, 113. [CrossRef]

51. Kanth, V.V.; Sasikala, M.; Rao, P.N.; Steffie Avanthi, U.; Rao, K.R.; Nageshwar Reddy, D. Pooled genetic analysis in ultrasound measured non-alcoholic fatty liver disease in Indian subjects: A pilot study. World J. Hepatol. 2014, 6, 435-442. [CrossRef] [PubMed]

52. Ching-Yeung Yu, B.; Kwok, D.; Wong, V.W. Magnitude of Nonalcoholic Fatty Liver Disease: Eastern Perspective. J. Clin. Exp. Hepatol. 2019, 9, 491-496. [CrossRef] [PubMed]

53. Lin, Y.C.; Chang, P.F.; Chang, M.H.; Ni, Y.H. Genetic variants in GCKR and PNPLA3 confer susceptibility to nonalcoholic fatty liver disease in obese individuals. Am. J. Clin. Nutr. 2014, 99, 869-874. [CrossRef]

54. Popescu, C.I.; Dubuisson, J. Role of lipid metabolism in hepatitis C virus assembly and entry. Biol. Cell 2009, 102, 63-74. [CrossRef]

55. Barba, G.; Harper, F.; Harada, T.; Kohara, M.; Goulinet, S.; Matsuura, Y.; Eder, G.; Schaff, Z.; Chapman, M.J.; Miyamura, T.; et al. Hepatitis $\mathrm{C}$ virus core protein shows a cytoplasmic localization and associates to cellular lipid storage droplets. Proc. Natl. Acad. Sci. USA 1997, 94, 1200-1205. [CrossRef] [PubMed]

56. Perlemuter, G.; Sabile, A.; Letteron, P.; Vona, G.; Topilco, A.; Chrétien, Y.; Koike, K.; Pessayre, D.; Chapman, J.; Barba, G.; et al. Hepatitis C virus core protein inhibits microsomal triglyceride transfer protein activity and very low density lipoprotein secretion: A model of viral-related steatosis. FASEB J. 2002, 16, 185-194. [CrossRef] [PubMed]

57. Agnello, V.; Chung, R.T.; Kaplan, L.M. A role for hepatitis C virus infection in type II cryoglobulinemia. N. Engl. J. Med. 1992, 327, 1490-1495. [CrossRef]

58. Fukuhara, T.; Ono, C.; Puig-Basagoiti, F.; Matsuura, Y. Roles of Lipoproteins and Apolipoproteins in Particle Formation of Hepatitis C Virus. Trends Microbiol. 2015, 23, 618-629. [CrossRef]

59. Zhu, C.; Zhang, R.; Liu, D.; Mukhtar, M.M.; Liu, W.; Peng, G.; Wang, K.; Hao, Q.; Xu, Y.; Liu, F.; et al. Association of functional polymorphism of $\mathrm{ApoB}$ promoter with hepatitis $\mathrm{C}$ virus infection. Clin. Chim. Acta 2009, 401, 124-127. [CrossRef] 
60. Harada, R.; Kimura, M.; Sato, Y.; Taniguchi, T.; Tomonari, T.; Tanaka, T.; Tanaka, H.; Muguruma, N.; Shinomiya, H.; Honda, H.; et al. APOB codon 4311 polymorphism is associated with hepatitis $\mathrm{C}$ virus infection through altered lipid metabolism. BMC Gastroenterol. 2018, 18, 24. [CrossRef]

61. Gu, Q.L.; Han, Y.; Lan, Y.M.; Li, Y.; Kou, W.; Zhou, Y.S.; Hai, X.J.; Yan, B.; Ci, C.H. Association between polymorphisms in the APOB gene and hyperlipidemia in the Chinese Yugur population. Braz. J. Med. Biol. Res. 2017, 50, e6613. [CrossRef]

62. Ghani, R.A.; Saqlain, M.; Zafar, M.M.; Jabeen, S.; Naqvi, S.M.; Raja, G.K. Identification of Metabolic risk phenotypes predisposing to Non-Alcoholic Fatty Liver Disease in a Pakistani Cohort. Pak. J. Med. Sci. 2017, 33, 121-126. [CrossRef]

63. Auton, A.; Brooks, L.D.; Durbin, R.M.; Garrison, E.P.; Kang, H.M.; Korbel, J.O.; Marchini, J.L.; McCarthy, S.; McVean, G.A.; Abecasis, G.R.; et al. A global reference for human genetic variation. Nature 2015, 526, 68-74. [CrossRef]

64. Miller, S.A.; Dykes, D.D.; Polesky, H.F. A simple salting out procedure for extracting DNA from human nucleated cells. Nucleic Acids Res. 1988, 16, 1215. [CrossRef]

(C) 2020 by the authors. Licensee MDPI, Basel, Switzerland. This article is an open access article distributed under the terms and conditions of the Creative Commons Attribution (CC BY) license (http://creativecommons.org/licenses/by/4.0/). 